\title{
OPEN Characteristics and risk assessment of occupational exposure to ultrafine particles generated from cooking in the Chinese restaurant
}

\begin{abstract}
Xiangjing Gao, Meibian Zhang, Hua Zou, Zanrong Zhou, Weiming Yuan, Changjian Quan \& Yiyao Cao $₫$

Ultrafine particles have been increasingly linked to adverse health effects in restaurant workers. This study aimed to clarify the exposure characteristics and risks of ultrafine particles during the cooking process, and to provide a reasonable standard for protecting the workers in the Chinese restaurant. The temporal variations in particle concentrations (number concentration (NC), mass concentration (MC), surface area concentration (SAC), and personal NC), and size distributions by number were measured by real-time system. The hazard, exposure, and risk levels of ultrafine particles were analyzed using the control banding tools. The NC, MC, and SAC increased during the cooking period and decreased gradually to background levels post-operation. The concentration ratios of MC, total NC, SAC, and personal NC ranged from 3.82 to 9.35. The ultrafine particles were mainly gathered at 10.4 and $100 \mathrm{~nm}$ during cooking. The exposure, hazard and risk levels of the ultrafine particles were high. These findings indicated that the workers during cooking were at high risk due to exposure to high levels of ultrafine particles associated with working activity and with a bimodal size distribution. The existing control strategies, including engineering control, management control, and personal protection equipment need to be improved to reduce the risk.
\end{abstract}

Cooking is an essential daily activity in households and also some commercial spaces. However, the cooking process can generate a large amount of particulate matter $(\mathrm{PM})$ of different sizes, ranging from ultrafine $(<0.1 \mu \mathrm{m})$ to accumulation $(0.1-2.0 \mu \mathrm{m})$ and coarse modes $(>2.0 \mu \mathrm{m})^{1}$. Large amounts of harmful PM that contain polycyclic aromatic hydrocarbons (PAHs), volatile organic compounds, and carbonyl compounds were generated during the cooking process ${ }^{2}$. Chowdhury et al. reported that $43.2 \%$ of the nanoparticles and $52.5 \%$ of microparticle exposure were from the cooking process ${ }^{3}$. Many studies have shown that cooking could be one of the major indoor sources of PM in total particle exposure ${ }^{4-7}$ and contribute to approximately $30 \%$ of the indoor particle concentration in the size range of $0.5-5 \mu \mathrm{m}^{8}$.

It has been found that particles at the nanoscale level cause more adverse health effects than larger particles with the same components ${ }^{9}$. In vitro and in vivo experiments have reported that the particles generated from cooking could deposit in the lungs, leading to adverse health effects on both the respiratory and cardiovascular systems, including decreased lung function, asthma, myocardial infarction, all-cause mortality, and cancer ${ }^{10-13}$. Epidemiological investigations have also demonstrated a significant link between negative health effects and exposure to PM from cooking ${ }^{7,14}$

Exposure characterization for PM from cooking has been a topic of academic interest in recent years. Many studies have investigated indoor particle dispersion and spatial exposure due to cooking activities. One study on indoor air pollution from gas cooking at home based on 24-h monitoring reported that ultrafine particle $\mathrm{NC}$ increased to $1.4 \times 10^{6}$ particles $/ \mathrm{cm}^{3}$ and the average $\mathrm{MC}$ of $\mathrm{PM}_{10}$ increased to $80 \mu \mathrm{g} / \mathrm{m}^{3}$ during cooking ${ }^{15}$. The 24-h time-resolved measurements of $\mathrm{PM}_{2.5}$ found that the median $\mathrm{PM}_{2.5}$ concentration was $79 \mu \mathrm{g} / \mathrm{m}^{3}$, and the NC of particle was $8.5 \times 10^{4}$ particles $/ \mathrm{cm}^{316}$. The emissions and indoor concentrations of PM in NC and MC under different cooking conditions were reviewed in a previous study ${ }^{17}$. This review found that cooking can 


\begin{tabular}{|c|c|c|c|c|c|c|}
\hline Monitoring types & Exposure metrics & Instruments & Particle sizes $(\mathrm{nm})$ & Measuring range & Sampling rate (L/min) & Log interval (min) \\
\hline \multirow{6}{*}{ Real-time monitoring } & Total NC & 3007 (TSI, USA) & $10-1000$ & $\begin{array}{l}0-100,000 \text { particles } / \mathrm{cm}^{3} \\
\left(\mathrm{pt} / \mathrm{cm}^{3}\right)\end{array}$ & 0.1 & 1 \\
\hline & Personal NC & $\begin{array}{l}\text { DiSCmini (TESTO, } \\
\text { Germany) }\end{array}$ & $<700$ & $0-5,000,000 \mathrm{pt} / \mathrm{cm}^{3}$ & 1.0 & 1 \\
\hline & Total respirable MC & $\begin{array}{l}\text { Dust Trak } 8533 \text { (TSI, } \\
\text { USA) }\end{array}$ & $100-1000$ & $0.01-150 \mathrm{mg} / \mathrm{m}^{3}$ & 3 & 1 \\
\hline & SAC & $\begin{array}{l}\text { Aero TrakTM } 9000 \text { (TSI, } \\
\text { USA) }\end{array}$ & $10-1000$ & $1-10,000 \mu \mathrm{m}^{2} / \mathrm{cm}^{3}$ & 2.5 & 1 \\
\hline & \multirow{2}{*}{$\begin{array}{l}\text { Size distribution by } \\
\text { number }\end{array}$} & SMPS 3034 (TSI, USA) & $10-487$ & $1-2.4 \times 10^{6} \mathrm{pt} / \mathrm{cm}^{3}$ & 1.0 & 3 \\
\hline & & OPS 3330 (TSI, USA) & $300-10,000$ & $0-3000 \mathrm{pt} / \mathrm{cm}^{3}$ & 1.0 & 1 \\
\hline
\end{tabular}

Table 1. Monitoring system for measuring the particles from cooking.

generate a notable volume of particles with a respirable size range, and the chemical compounds included alkanes, fatty acids, dicarboxylic acids, lactones, PAHs, alkenones, and sterols. Previous studies of exposure assessment mostly focused on the characteristics of PM associated with residential cooking activities at home. Few studies have reported the characteristics of ultrafine particles exposed to kitchen workers in Chinese restaurants. Due to the rapid development of the catering industry and the proximity these workers have to PM, a large number of occupational workers in the kitchen may be at high risk of exposure to ultrafine particles, which should be a cause for concern.

Exposure characterization is the basis for exposure assessment and risk assessment. Along with the exposure characterization, a carcinogenic risk assessment of the chemical compositions of the ultrafine particles involved in cooking was conducted. A health risk assessment of the volatile organic compounds (VOCs) from cooking in restaurants has been reported ${ }^{18}$. A chemical characterization and cancer risk assessment for airborne carbonyls, particulate-bound PAHs, and heavy metals was conducted under low ventilation conditions in eight categories of commercial restaurants ${ }^{19}$. Previous risk assessment studies have focused on the chemical components involved in cooking. However, the components of the ultrafine particles generated from cooking are complex, and their respective exposure characterization is difficult to obtain. Moreover, most occupational exposure limits for the components of the ultrafine particles from cooking are lacking. In order to manage the risks of the ultrafine particles from cooking, a feasible and easy risk assessment strategy that can classify the substance into risk categories with recommended control measures based on limited physicochemical and task/scenario information should be introduced. The control banding (CB) tools evaluate the hazard risk and exposure risk by setting different parameters, and then obtain risk levels and protective measures based on a tiered approach. The CB tools, which offer simplified guidance for managing the risks from exposure to substances without toxicological and/ or detailed exposure information, are applicable methods and have been used for risk assessments of different ultrafine particle exposure levels in various work environments ${ }^{20-23}$. In previous studies, CB tools were compared qualitatively and quantitatively under experimental or real nanomaterial exposure scenarios, and different tools to estimate hazard and exposure bands can result in different outcomes and preventive recommendations ${ }^{22-25}$.

The processes used in Chinese restaurants generally operate under rapid high-heat conditions, such as frying and roasting, which are different from Western restaurants, may contribute significantly to the emissions of ultrafine particles. Knowledge of the exposure characteristics and risk assessments of ultrafine particles for workers in Chinese restaurants is limited. In order to bridge the above research gaps, it is necessary to understand the exposure characteristics and risks of ultrafine particles generated during cooking comprehensively, and provide a basis for developing a reasonable control strategy to reduce the health risks for workers in Chinese restaurants.

In order to understand the exposure characteristics and the risks of ultrafine particles during cooking, and provide a basis for developing a reasonable control measures to reduce the health risks for workers, the following three aspects were investigated in this study: (1) the temporal variation in total number concentrations of particles (namely, total NC, total respirable MC, personal NC, and SAC) and size distributions by number; (2) the risk levels of workers exposed to ultrafine particles; (3) the control measures to be improved for reducing the health risks of workers.

\section{Materials and methods}

Description of workplace. One commercial Chinese restaurant in the Zhejiang Province of East China was selected for a field investigation. The major foods of the restaurant that were served covered meats, vegetables, fishes, shrimp, eggs, and noodles. The main cooking methods included stir-frying, pan-frying, and deepfrying, which were generally operate under rapid high-heat conditions. The fuel used in this restaurant was natural gas. In each shift there were four chefs and five prep cooks wearing working clothes without respiratory protective equipment. Their daily working time is about $4 \mathrm{~h}$. The kitchen door was kept closed at all times. A local exhaust ventilation (LEV) system, which was kept on during cooking, covered all of the stoves in the kitchen. The LEV is a side suction exhaust hood, which is about $0.8 \mathrm{~m}$ away from the gas stove.

Monitoring systems and quality control. Table 1 shows the real-time monitoring system for particles from the cooking process. The total NC was determined using an ultrafine particle counter (Model 3007; TSI, Shoreview, MN). The personal NC and particle size were measured using a Diffusion Size Classifier Miniature (DiSCmini, Testo, Germany), which can measure the number and average size of particles (approxi- 


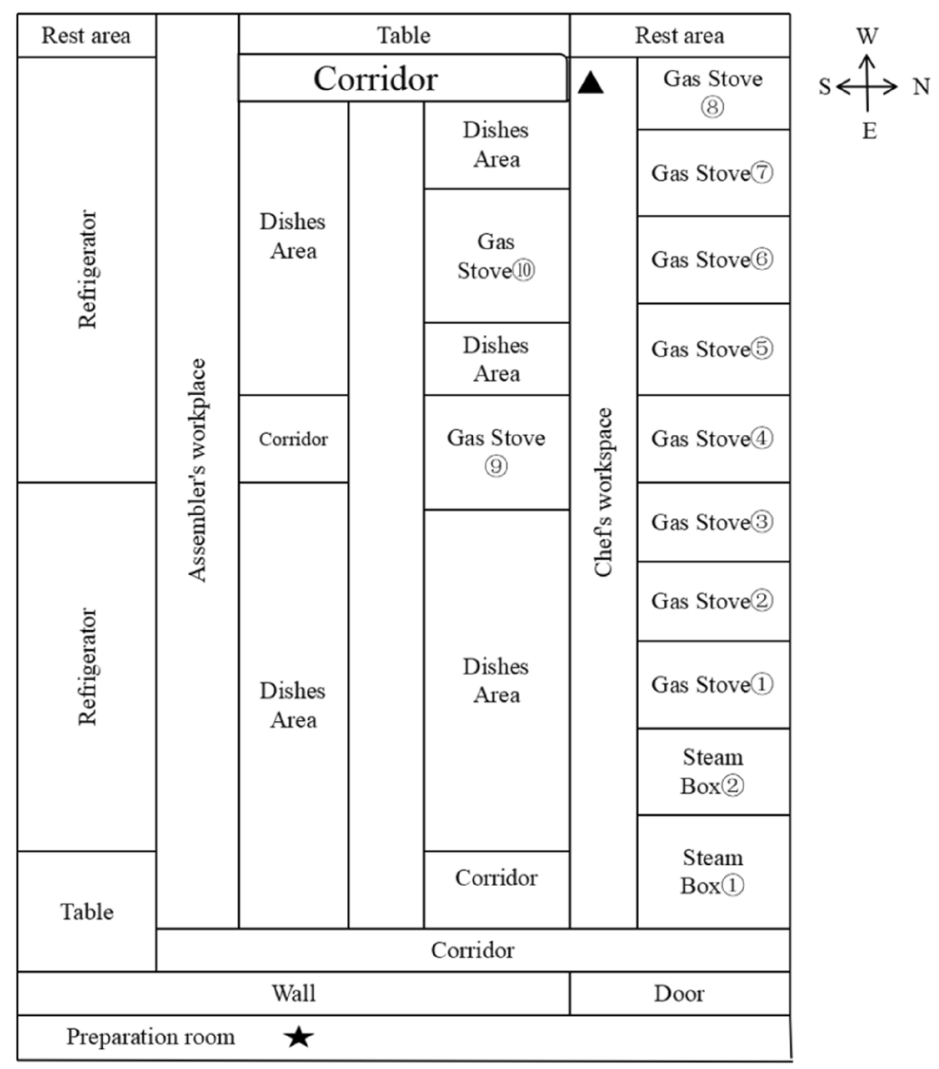

Figure 1. Workshop layout and sampling locations marked with a triangle and an asterisk. Sampling filled star: background; filled triangle: operation location.

mately $<0.7 \mu \mathrm{m}$ ) in the air. The MC was tested using a real-time aerosol monitor (DustTrak 8533, TSI, Shoreview, MN). A surface area monitor (Aero TrakTM 9000, TSI, USA) was used to determine the alveolus deposition model and tracheobronchial (TB) deposition model of SAC. A scanning mobility particle sizer (SMPS, Model 3034, TSI, USA) and optical particle sizer (OPS, Model 3330, TSI, USA) were used jointly to capture the particle size distribution and $\mathrm{NC}$ covering the size range from $10.4 \mathrm{~nm}$ to $10 \mu \mathrm{m}$. The mode size, median size, arithmetic mean size, and geometric mean size were obtained from the data output of the SMPS and OPS. The air velocity was measured by hot-wire anemometer (9515, TSI, USA).

All of instruments used were calibrated by its own manufactures (TSI and Testo) once a year. Before measuring, the instruments were set to zero and their inlet filter were cleaned in clean environment. Then, the instruments mode were set as recording mode and set continuous measurement time and data recording interval time.

Sampling and testing strategies. The sampling process was performed in October 2019. After the field investigation, concentration screening using the condensation particle counter (CPC) was conducted to identify the potential source of particle emissions, as reported in our previous study ${ }^{21,22}$. The sampling protocol was as follows: (1) Background measurements: background particles from the atmosphere were collected in the preparation room, as shown in Fig. 1 (asterisk location). (2) Area sampling based on activity: the sampling locations were selected near the operation location, considering several factors, such as air movement and currents, work tasks, temperature of the heat source, and whether the location could allow for the placement of large instruments without affecting normal work activities. In this study, all of the stoves were substantial sources of ultrafine particles. However, the corridor that the chefs stand in was too narrow to place the testing instruments in. Hence, the stove numbered 8, which was near the corridor and the rest area, was selected as the sampling location, as shown in Fig. 1 (triangle labeling). Area sampling covered one complete workflow. The instruments' inlets were positioned $1.3 \mathrm{~m}$ above the floor and close to the stove. (iii) Personal sampling: one chef and prep cook station were selected as the personal sampling location, and the sampling period covered one complete workflow. The sampler was fixed approximately $1.3 \mathrm{~m}$ above the floor and $30 \mathrm{~cm}$ away from the breathing zone of chef or prep cook.

The total concentrations were revised using background concentrations to obtain the concentration ratios (CR) (sampling location vs. background), which reflect the degree of nanoparticles released from the particle generation source. The risk ratio (RR), a relative risk level, which is defined as the ratio between the risk level obtained from the $\mathrm{CB}$ tool and the maximum risk level for that tool was introduced to compare risk assessment results across different tools. Similarly, the exposure band ratio is defined as the ratio between the exposure level and the maximum exposure level for the tool, whereas the hazard band ratio is the ratio between the hazard 


\begin{tabular}{|l|l|l|}
\hline CB tools & Materials information requested & Oil fume \\
\hline \multirow{5}{*}{ Stoffenmanager-nano } & Product appearance & Liquid with medium viscosity (like oil) \\
\cline { 2 - 3 } & $\begin{array}{l}\text { Do you know the exact concentration of the nano component in } \\
\text { the product? }\end{array}$ & No \\
\cline { 2 - 3 } & Concentration & Main component (50-99\%) \\
\cline { 2 - 3 } & Does the product contain fibers/fiber like particles? & No \\
\cline { 2 - 3 } & Inhalation hazard & Carcinogenic and mutagenic \\
\cline { 2 - 3 } & Is the primary particle diameter larger than 50 nm? & No \\
\hline \multirow{5}{*}{ Nanotool-parent material } & Current engineering control & Local exhaust ventilation \\
\cline { 2 - 3 } & Carcinogen & Yes \\
\cline { 2 - 3 } & Reproductive hazard & No \\
\cline { 2 - 3 } & Mutagen & Yes \\
\cline { 2 - 3 } & Dermal hazard & No \\
\cline { 2 - 3 } & Asthmagen & No \\
\hline \multirow{5}{*}{ Nanotool-nanoscale material } & Surface reactivity & Unknown \\
\cline { 2 - 3 } & Particle shape & Anisotropic \\
\cline { 2 - 3 } & Particle diameter & $11-40 \mathrm{~nm}$ \\
\cline { 2 - 3 } & Solubility & Insoluble \\
\cline { 2 - 3 } & Carcinogen & Yes \\
\cline { 2 - 3 } & Reproductive hazard & No \\
\cline { 2 - 3 } & Mutagen & Yes \\
\cline { 2 - 3 } & Dermal hazard & No \\
\cline { 2 - 3 } & Asthmagen & No \\
\hline \multirow{5}{*}{} & & \\
\hline
\end{tabular}

Table 2. Hazard input data of the evaluated materials required by different control banding (CB) tools.

\begin{tabular}{|c|c|c|}
\hline CB tools & Materials information requested & Cooking oil fume \\
\hline \multirow{10}{*}{ Stoffenmanager Nano } & Task characterization & Chemical vapor condensation \\
\hline & Is the task being carried out in the breathing zone of an employee (distance head-product $<1 \mathrm{~m}$ ) & Yes \\
\hline & Is there more than one employee carrying out the same task simultaneously & Yes \\
\hline & Is the working room being cleaned daily? & Yes \\
\hline & $\begin{array}{l}\text { Are inspections and maintenance of machines/ancillary equipment being done at least monthly to ensure good } \\
\text { condition and proper functioning and performance? }\end{array}$ & No \\
\hline & Volume of the working room & $<100 \mathrm{~m}^{3}$ \\
\hline & Ventilation of the working room & Mechanical and or natural ventilation \\
\hline & Local control measures & Local exhaust ventilation \\
\hline & Is the employee situated in a cabin & No \\
\hline & Is personal protective equipment applied? & No \\
\hline \multirow{5}{*}{ Nanotool } & Chemical vapor condensation & $11-100 \mathrm{mg}$ \\
\hline & Current Engineering Control & Local exhaust ventilation \\
\hline & Number of Employees with Similar Exposure & $6-10$ \\
\hline & Frequency of Operation (annual) & Daily \\
\hline & Operation duration & $>4 \mathrm{~h}$ \\
\hline
\end{tabular}

Table 3. Exposure scenario data input for the particles generated from cooking.

level and the maximum hazard level for the tool. All of the ratios were used to compare the assessment results obtained from different CB tools.

Methodology for risk assessment. According to previous studies, the Stoffenmanager-Nano and Nanotool, which are appropriate for nanoparticles and have a comprehensive advantage in risk assessment ${ }^{22,23}$, were selected for this study. The CB methodology for CB tools is briefly described as follows: The StoffenmanagerNano (http://nano.stoffenmanager.nl/), which follows a stepwise binary decision tree and provides three risk levels ${ }^{26,27}$, was developed by the Organization for Applied Scientific Research based in the Netherlands. The Nanotool (http://www.controlbanding.net/) was developed by Paik and Zalk et al. at the Lawrence Livermore National Laboratory, $\mathrm{USA}^{28}$. It assigns the hazard and exposure levels using a point scoring system. The hazard and exposure levels are combined to obtain the risk level in a two-dimensional decision matrix, then is equally divided into four levels ${ }^{21,28}$. Table 2 shows the hazard input data, and Table 3 shows the exposure input data for 
the CB tools. The hazards were determined from information presented as data on the shape, concentration, surface activity, and toxicity of particles, which includes carcinogenicity, mutagenicity, and reproductive toxicity. The exposure levels were determined by the substance emission potential, activity emission potential, and exposure control, as previously reported.

Statistical analysis. The differences in the particle concentrations corresponding to different periods was analyzed using the one-way analysis of variance (ANOVA); the LSD comparison method was used when variances were equal, and the Dunnett T3 comparison method was used when the variances were heterogeneous.

Ethics approval. This study does not involve experimental animals or human participants.

\section{Results}

Temporal variations in the total particle concentrations. The temporal variations in the total particle concentrations are shown in Fig. 2. The total NC during the activity period was higher than that during the non-activity period or background. The highest total NC of the activity period reached $2 \times 10^{5} \mathrm{pt} / \mathrm{cm}^{3}$ around $30 \mathrm{~min}$ after cooking, which was approximately four times higher than that of the non-activity period or background. The highest SACs of the activity period in the alveolus model and TB model were $2400 \mu \mathrm{m}^{2} / \mathrm{cm}^{3}$ and $800 \mu \mathrm{m}^{2} / \mathrm{cm}^{3}$, respectively, which were approximately five times and three times higher than that of the background (non-activity period), respectively. The $\mathrm{MC}$ of $\mathrm{PM}_{2.5}$ during the working activity period reached $0.8 \mathrm{mg} /$ $\mathrm{cm}^{3}$, approximately ten times higher than that of the non-activity period. The highest NC of the chef reached a peak of $2.6 \times 10^{6} \mathrm{pt} / \mathrm{cm}^{3}$ at 12:35 during the activity period, which was more than 10 times higher than the nonactivity period and the total NC. The NC of the prep cook was lower than $6 \times 10^{4} \mathrm{pt} / \mathrm{cm}^{3}$, which was approximately 100 times lower than that of the chef. The total NC varied with working activities, which increased after work started and decreased gradually to background level after the activity stopped. The total SAC varied with the activities, but was slightly inconsistent with the time. The total SAC increased before the activity started, and decreased slowly after the operation stopped. The SAC in the alveolus model was higher than that in the TB model, but the variations in the SAC in the alveolus and TB models were similar. The MC of $\mathrm{PM}_{1}$ and $\mathrm{PM}_{2.5}$ increased near the end of the activity period, and decreased to the background level approximately $30 \mathrm{~min}$ after the activity stopped. The total NC and SAC fluctuated greatly during the activity period, while MC performed steadily. Figure 2C shows that the size of the particles exposed to the chef was approximately $40 \mathrm{~nm}$ during cooking, while the background particle size was larger than $60 \mathrm{~nm}$. The largest size of the background particles reached $160 \mathrm{~nm}$. The size of the particles exposed to the prep cook remained steady, at around $60 \mathrm{~nm}$.

Total ultrafine particle concentrations during cooking, the non-activity period, and the background. The total particle concentrations during different periods are listed in Table 4. The NC, $\mathrm{PM}_{1}, \mathrm{PM}_{2.5}$, and SAC during cooking were $14.51 \pm 2.50 \diamond 10^{4} / \mathrm{cm}^{3}, 0.25 \pm 0.11 \mathrm{mg} / \mathrm{m}^{3}, 0.28 \pm 0.13 \mathrm{mg} / \mathrm{m}^{3}, 799.20 \pm 407.79 \mu \mathrm{m} /$ $\mathrm{cm}^{3}$, and $236.45 \pm 129.84 \mu \mathrm{m} / \mathrm{cm}^{3}$, respectively, which were significantly higher than that of the background $(p<0.01)$. The NC, $\mathrm{PM}_{1}, \mathrm{PM}_{2.5}$, and SAC during the non-activity period were $2.82 \pm 0.77 \diamond 10^{4} / \mathrm{cm}^{3}, 0.07 \pm 0.02 \mathrm{mg} /$ $\mathrm{m}^{3}, 0.07 \pm 0.02 \mathrm{mg} / \mathrm{m}^{3}, 136.86 \pm 47.98 \mu \mathrm{m} / \mathrm{cm}^{3}$, and $45.92 \pm 23.64 \mu \mathrm{m} / \mathrm{cm}^{3}$, respectively, which were similar to that of the background. The $\mathrm{CR}$ for $\mathrm{NC}, \mathrm{PM}_{1}, \mathrm{PM}_{2.5}$, and SAC during cooking ranged from 3.82 to 5.40. The NCs of the chef and prep cook during cooking were $11.53 \pm 6.06 \diamond 10^{5} / \mathrm{cm}^{3}$ and $4.63 \pm 0.64 \diamond 10^{5} / \mathrm{cm}^{3}$, respectively, which were significantly higher than those during the non-activity period.

Particle size and size distribution. Figure 3 shows the temporal variations in the mode, median, mean, and geometric sizes of the ultrafine particles from cooking and the background. The median, mean, geometric mean, and mode sizes of particles, which were determined using the SMPS, remained relatively stable during the activity period, ranging from 15 to $50 \mathrm{~nm}$. In contrast, these particle sizes ranged from 45 to $85 \mathrm{~nm}$ before operations started. The mode size of the particles, which was determined by the SMPS, exhibited greater variations. The variations in particle size monitored by OPS were different from those determined by the SMPS. The changes in the median, mean, geometric mean, and mode sizes of particles remained steady, ranging from 0.35 to $0.45 \mu \mathrm{m}$. The order of particle sizes by type monitored by SMPS or OPS was as follows: mode $<$ median $<$ geometric mean $<$ mean.

Figure 4 shows a typical particle size distribution $\left(\mathrm{dN} / \mathrm{dLogDp}\right.$, particle $\left./ \mathrm{cm}^{3}\right)$ as a function of time, as measured by SMPS and OPS. The particle diameters were 10.4-96.5 nm for the SMPS named Nano DMA, 103.7-469.8 $\mathrm{nm}$ for the SMPS named Long DMA, and 0.3-10 $\mu \mathrm{m}$ for OPS. The total NC of the particles with a small size increased at approximately 11:50 am around $30 \mathrm{~min}$ after cooking. Particles during the activity period were mainly smaller than $150 \mathrm{~nm}$, and the highest number reached $5.5 \times 10^{5} \mathrm{pt} / \mathrm{cm}^{3}$ (Fig. 4A), which appeared at $10.4 \mathrm{~nm}$ and $100 \mathrm{~nm}$. The number of particles greater than $150 \mathrm{~nm}$ was lower than $2 \times 10^{5} \mathrm{pt} / \mathrm{cm}^{3}$. The OPS measured showed that particles larger than $374 \mathrm{~nm}$ presented concentrations lower than $1.4 \times 10^{4} \mathrm{pt} / \mathrm{cm}^{3}$. The $\mathrm{NC}$ of the particles, which ranged from $10.4 \mathrm{~nm}$ to $0.4 \mu \mathrm{m}$, significantly decreased after the non-activity period, as illustrated in Fig. 4.

Risk assessment and risk management. Table 5 shows the results of the risk assessment from the CB tools and the suggested preventive measures according to the NIOSH regulation ${ }^{29}$. The hazard band ratios given by the Stoffenmanager Nano and Nanotool were 0.8 and 0.75 , respectively. The exposure band ratios given by different CB tools were the same (0.75). The RRs given by the two tools were 0.67 and 0.75 , respectively. The capture point velocity of exhaust hood is $0.2 \mathrm{~m} / \mathrm{s}$ measured by the hot-wire anemometer, which is far below the regulation 
A

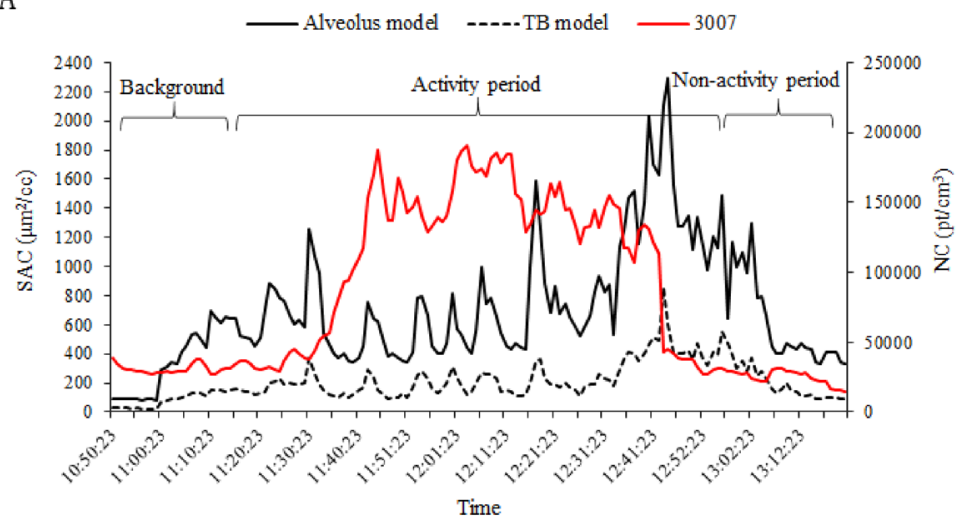

B

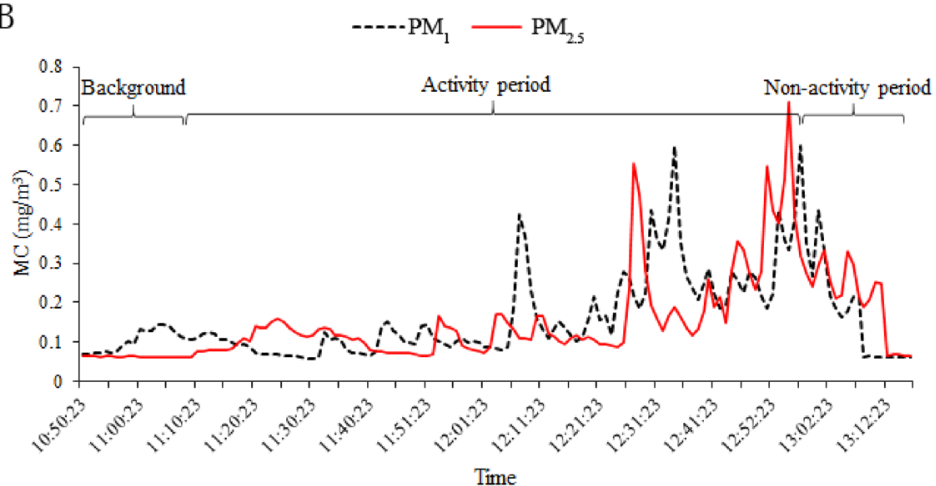

C

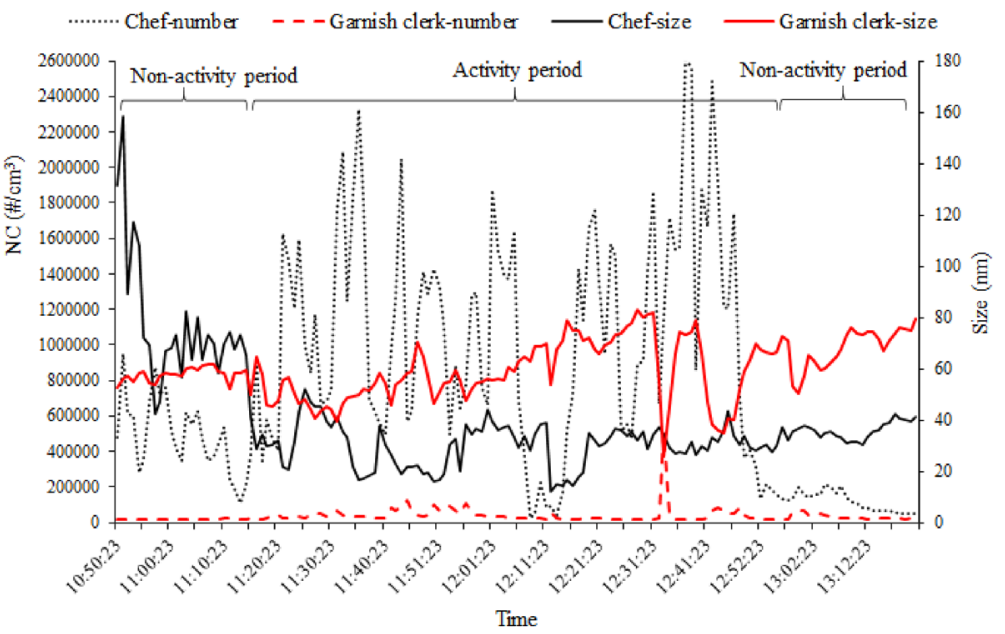

Figure 2. Temporal variations in total particle concentrations associated with working activities. (A) Temporal variations in total surface area concentration (SAC) and number concentrations (NC) at background and operation locations. (B) Temporal variations in total respirable mass concentration (MC) at the background and operation locations. (C) Temporal variations in personal NC and its size during the working and non-activity periods.

of technical specifications for capture velocity for LEV facilities (AQ/T4274-2016) ${ }^{30}$ in China. The high exposure level and risk level suggested that protective measures should be developed and implemented. According to the NIOSH regulation, five steps are needed, such as eliminating, substitution, engineering controls, administrative controls, and personal protective equipment (PPE). As eliminating and substitution of ultrafine particles are not be possible during cooking, the following hierarchy of controls should be used to implement ${ }^{29}$ : engineering controls, administrative controls, and PPE. The current control measures and the additional control measures to be improved are listed in Table 5. 


\begin{tabular}{|c|c|c|c|c|c|c|}
\hline \multirow[b]{2}{*}{ Metrics } & \multicolumn{2}{|l|}{ Cooking } & \multicolumn{2}{|l|}{ Background } & \multicolumn{2}{|l|}{ Non-activity period } \\
\hline & Mean \pm SD & CR & Mean \pm SD & CR & Mean \pm SD & CR \\
\hline $\mathrm{NC}\left(10^{4} \mathrm{pt} / \mathrm{cm}^{3}\right)$ & $14.51 \pm 2.50(\mathrm{n}=65)^{\mathrm{a}}$ & 5.40 & $2.69 \pm 0.83(\mathrm{n}=45)$ & 1.00 & $2.82 \pm 0.77(\mathrm{n}=40)$ & 1.05 \\
\hline $\mathrm{PM}_{1}\left(\mathrm{mg} / \mathrm{m}^{3}\right)$ & $0.25 \pm 0.11(\mathrm{n}=65)^{\mathrm{a}}$ & 3.85 & $0.07 \pm 0.01(\mathrm{n}=45)$ & 1.00 & $0.07 \pm 0.02(\mathrm{n}=40)$ & 1.00 \\
\hline $\mathrm{PM}_{2.5}\left(\mathrm{mg} / \mathrm{m}^{3}\right)$ & $0.28 \pm 0.13(\mathrm{n}=65)^{\mathrm{a}}$ & 3.93 & $0.07 \pm 0.01(\mathrm{n}=45)$ & 1.00 & $0.07 \pm 0.02(\mathrm{n}=40)$ & 1.01 \\
\hline $\operatorname{SAC}_{\text {A model }}\left(\mu \mathrm{m}^{2} / \mathrm{cm}^{3}\right)$ & $799.20 \pm 407.79(\mathrm{n}=65)^{\mathrm{a}}$ & 3.82 & $106.46 \pm 42.28(\mathrm{n}=45)$ & 1.00 & $136.86 \pm 47.98(n=40)$ & 1.28 \\
\hline $\mathrm{SAC}_{\mathrm{TB} \text { model }}\left(\mu \mathrm{m}^{2} / \mathrm{cm}^{3}\right)$ & $236.45 \pm 129.84(\mathrm{n}=65)^{\mathrm{a}}$ & 5.15 & $40.09 \pm 28.32(\mathrm{n}=45)$ & 1.00 & $45.92 \pm 23.64(\mathrm{n}=40)$ & 1.15 \\
\hline Personal NC-chef $\left(10^{5} \mathrm{pt} / \mathrm{cm}^{3}\right)$ & $11.53 \pm 6.06(\mathrm{n}=75)^{\mathrm{b}}$ & 9.35 & - & - & $1.23 \pm 0.81(\mathrm{n}=58)$ & 1.00 \\
\hline Personal NC-prep cook $\left(10^{4} \mathrm{pt} / \mathrm{cm}^{3}\right)$ & $4.63 \pm 0.64(\mathrm{n}=75)^{\mathrm{b}}$ & 2.28 & - & - & $2.02 \pm 0.72(\mathrm{n}=58)$ & 1.00 \\
\hline
\end{tabular}

Table 4. Total particle concentrations during cooking, background, and non-activity period. ${ }^{\mathrm{a}} p<0.01$, as compared with the background. ${ }^{\mathrm{b}} p<0.01$, compared with the non-activity period.
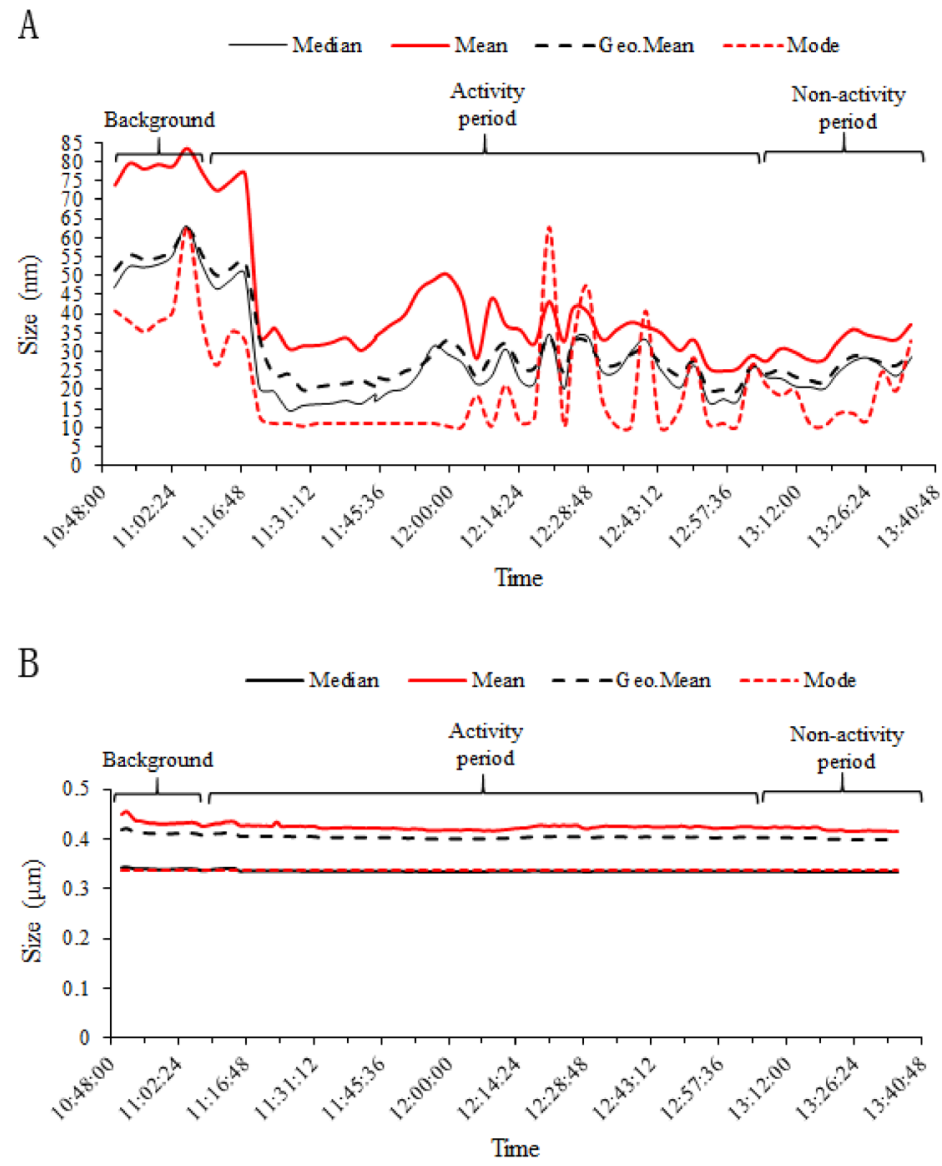

Figure 3. Temporal variations in mode, median, mean, and geometric mean particle sizes. (A) Mode, median, mean, and geometric mean size of the particles monitored by SMPS at background and operation locations. (B) Mode, median, mean, and geometric mean size of the particles monitored by optical particle sizer (OPS) at the background and operation locations.

\section{Discussion}

Considerable progress has been made in research on cooking emissions in China over the last 20 years. Studies have focused on the concentrations of PM, PAHs and VOCs, emission rates, and influential factors (such as the cooking method, types of oil, and kinds of stoves). In this study, ultrafine particles from the cooking process were collected, and their exposure characteristics and risk assessment were investigated. To our knowledge, this is the first study to comprehensively evaluate ultrafine particles' exposure risks and control measures in a Chinese restaurant using a combination of exposure characterization and the $\mathrm{CB}$ tools.

The total NC and total respirable MC during cooking were significantly higher than those from the background or during the non-activity period (Table 4). The CR of total NC was up to 5.4, and the CR of MC ( $\mathrm{PM}_{1}$ and $\mathrm{PM}_{2.5}$ ) were similar (3.85 and 3.93). These results suggested that the cooking process conducted in the Chinese 
A SMPS-NanoDMA

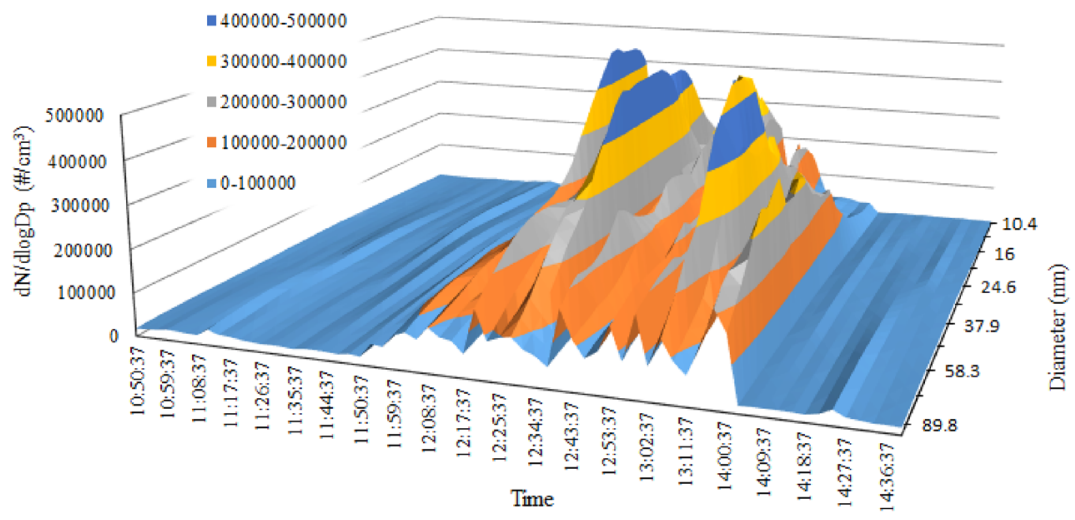

B

SMPS-LongDMA

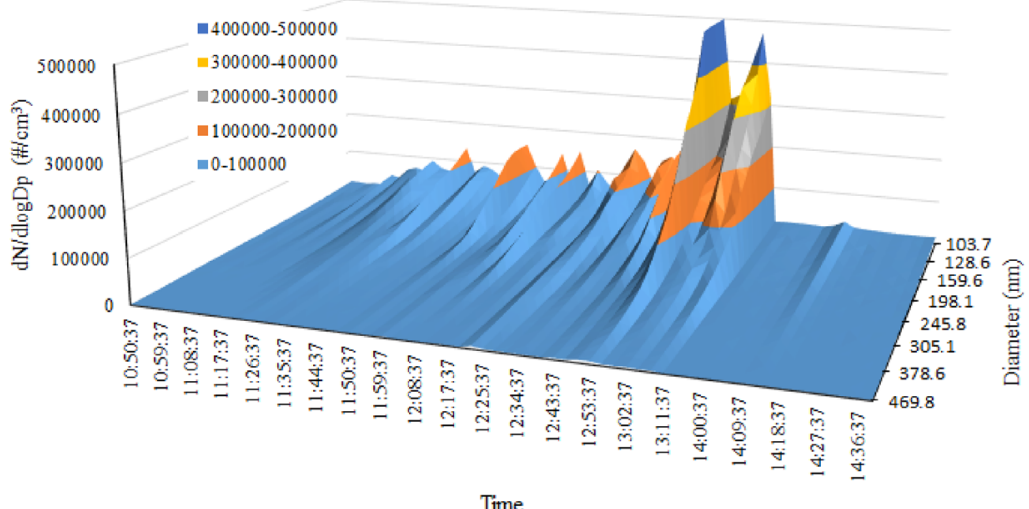

C

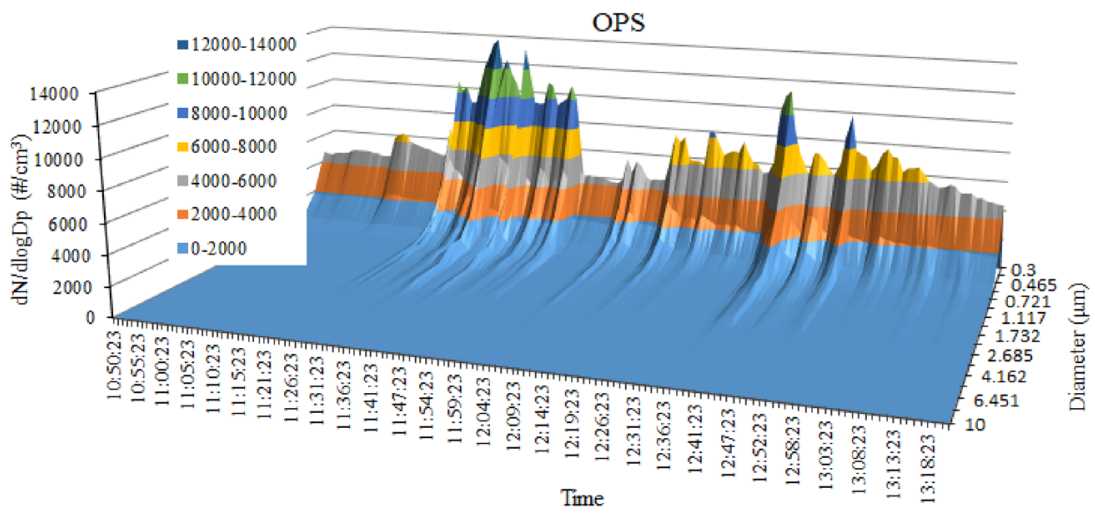

Figure 4. Real-time particle size spectrum. (A) scanning mobility particle spectrometer (SMPS) with Nano dust/aerosol monitor (DMA); (B) SMPS with Long DMA; (C) optical particle sizer (OPS). Most of the particles were smaller than $100 \mathrm{~nm}$, and the highest number reached $5.5 \times 10^{5} \mathrm{pt} / \mathrm{cm}^{3}$ at $10.4 \mathrm{~nm}$ and $100 \mathrm{~nm}$.

restaurant was able to generate nanoparticles at high levels (in particular, in higher NC and SAC). Similarly, the personal NC during cooking was significantly higher than that during the non-activity period, including the total NC, which provided direct evidence that workers were exposed to high NC levels of ultrafine particles during the cooking process. This result was supported by studies on emissions of air pollutants from cooking, which reported that the average NC of ultrafine particles ranged between $0.354 \times 10^{6}$ and $6.643 \times 10^{6} \mathrm{pt} / \mathrm{cm}^{3}$, and the MC of PM2.5 released during cooking is approximately $28.7-44,920 \mu \mathrm{g} / \mathrm{m}^{3}$ in commercial kitchens ${ }^{31-34}$. The phenomenon that personal NC was higher than the total NC suggested that the real exposure concentrations 


\begin{tabular}{|c|c|c|c|c|c|}
\hline Tools & Hazard band ratio & Exposure band ratio & RR & Existing control measures & Additional control measures to be improved \\
\hline Stoffenmanager Nano & 0.8 & 0.75 & 0.67 & \multirow[b]{2}{*}{$\begin{array}{l}\text { (1) Engineering controls: the gas stove was } \\
\text { equipped with a LEV. The capture velocity of } \\
\text { LEV was insufficient } \\
\text { (2) Occupational health management system: } \\
\text { regular occupational health training, reduced } \\
\text { exposure time, and occupational health examina- } \\
\text { tions for workers. The preventative maintenance } \\
\text { schedule and sensitive indicators for ultrafine } \\
\text { particles were missing }\end{array}$} & \multirow[b]{2}{*}{$\begin{array}{l}\text { (1) Engineering controls: the exhaust speed of } \\
\text { LEV needs to be increased, including the redesign } \\
\text { of hood for total enclosure } \\
\text { (2) Occupational health management system: the } \\
\text { preventative maintenance schedule for ensuring } \\
\text { the effectiveness of engineering control measures } \\
\text { should be established; sensitive indicators for } \\
\text { ultrafine particles need to be developed in occu- } \\
\text { pational health examination } \\
\text { (3) PPE: the NIOSH-certified N95 or P100 } \\
\text { filtering facepiece respirators should be used, and } \\
\text { regular inspection should be conducted to ensure } \\
\text { workers are properly wearing the PPE }\end{array}$} \\
\hline Nanotool & 0.75 & 0.75 & 0.75 & & \\
\hline
\end{tabular}

Table 5. The outcomes of risk assessment and management.

were higher than expected, while most of the monitoring was conducted on the total NC. The SAC in the alveolus and TB models during cooking was higher than those from the background or during the non-activity period (Table 4), which was consistent with the total NC. This result was confirmed by a study on the deposition of ultrafine particles in the lungs, outdoors and indoors during cooking, which found that the number of particles that had been deposited deep into the lungs during cooking was 10 times higher indoors than outdoors ${ }^{35}$.

As Fig. 2 shows, the temporal variations of total NC, SAC, and personal NC exhibited an activity-related characteristic, which consisted of a background level, a starting phase, a steady-state phase and finally, a decline phase. The total NC and SAC varied with working activities, while total MC was not consistent with activity in time. The correlation between total NC and SAC was 0.786 , the correlation between NC and MC was 0.218 , the correlation between SAC and MC was 0.380 . The correlations between total NC, SAC, and MC has been explored in previous studies about ultrafine particles using real-time measurements ${ }^{36,37}$, which supported our finding. The high correlation between NC and SAC might be related to the fact that the 3007 counts the number of particles, the AeroTrak charges particles in a unipolar charge and then converting the number of particles into surface area. The reason for the phenomenon that MC was not increased higher than background immediately after cooking started might be that, with an average mode size of 40 , such a nano-size of particles does not interact strongly with electromagnetic radiation of optical wavelength, and cannot be detected efficiently by a light-scattering photometer ${ }^{38}$. This result suggested that the MC was not not as sensitive as the NC or the SAC in mesuring ultrafine particles. This finding was confirmed by a field study that reported that the total NC of nanoparticles was 100 times higher than the exposure limit, and MC was no longer an appropriate evaluation metric ${ }^{39}$. The reason of differences in trends for temporal variations of total NC and personal NC may be related with the range of particle size meaured by different instruments, and the monitoring location. The personal NC obtained from Discmini was fixed approximately $1.3 \mathrm{~m}$ above the floor and $30 \mathrm{~cm}$ away from the breathing zone of chef, which can provide a more realistic reaction of the variation of primary released particles. While the total NC obtained from 3007 which was located farther than Discmini. The personal NC presented more sensitive to the cooking activity. As reported in a previous study, the PM level could be much higher when the oil temperature exceeded the oil smoke point ${ }^{1}$. This was consistent with our results, which showed that the NC of the chef got from Discmini fluctuated greatly during the activity period as the stoves fired intermittently.

The results of temporal variation in mode, median, mean, and geometric sizes showed that their trends were similar. The distance of change in arithmetic mean, medium, and geometric mean sizes was similar, but less sensitive than that for modal size. The size distribution data from SMPS was different from that obtained from OPS. One of the reason could be the different size range of instruments, as the range of particles SMPS measured was $10-487 \mathrm{~nm}$, and the range of OPS measured was $0.3-10 \mu \mathrm{m}$. Another reason might be the different principles of detection, which were electrical mobility diameter for SMPS and light scattering equivalent diameter for OPS. As Fig. 4 showed, the predominant particles were below $150 \mathrm{~nm}$ and changed a lot, while the particles with size bigger than $0.3 \mu \mathrm{m}$ occupied a small percentage. Figure 4 showed that the particles released from the cooking process were mainly smaller than $150 \mathrm{~nm}$. The highest $\mathrm{NC}$ appeared at $10.4 \mathrm{~nm}$ and $100 \mathrm{~nm}$, which presented a bimodal size distribution. The high NC at $100 \mathrm{~nm}$ suggested that the ultrafine particles in cooking fumes could agglomerate. The total NC of particles less than $100 \mathrm{~nm}$ was approximately 10 times higher than that of particles above $100 \mathrm{~nm}$. This was confirmed by a previous study on environmental chemistry in a family kitchen, which found that cooking particles were predominantly in the ultrafine mode ${ }^{40}$.

The exposure band ratio, hazard band ratio, and RR of this scenario given by two CB tools were similar (higher than 0.65 ), which belonged to high levels. The high proportion of carcinogens in cooking fumes ${ }^{41}$ supported the result of high hazard levels obtained from CB tools. The high exposure risk was confirmed with the results of NC, MC, SAC, and personal NC, which showed high CRs during the cooking process (Table 4). Epidemiological studies have reported that cooking oil fumes contain many carcinogens $s^{42}$, and their exposure could increase the risk of cancer ${ }^{43,44}$, which provides evidence for the high hazard risk. Controlling exposures to occupational hazards is the fundamental method of protecting workers under high exposure risk. According to the NIOSH regulation, a hierarchy of controls, including elimination, substitution, engineering controls, administrative controls, and personal protective equipment, has been used as a means of determining how to implement feasible and effective controls ${ }^{29}$. For the restaurant investigated in this study, elimination and substitution are not viable options, the most desirable alternative for mitigating occupational hazards is to employ engineering controls. Both of outcomes of two CB tools suggested preventive measures included LEV, which 
suggested that the existing LEV in the restaurant was not effective. The existing LEV in the restaurant is a kind of exhaust hood with suction fans, which is $0.8 \mathrm{~m}$ away from gas stove. The capture point velocity of exhaust hood is only $0.2 \mathrm{~m} / \mathrm{s}$, which is far below the regulation of China and the possible reason of low capture effective. The results of concentrations and risk assessment suggested that the existing control measures do not reduce exposures to an acceptable level. The reason might be the low velocity, the location of the exhaust hood mouth, the rising airflow from a hot process. To protect workers in similar restaurants, the most desirable alternative is to employ the following additional measures before detailed regulations being enacted: (1) the exhaust speed of LEV at the gas stove needs to be increased, including the redesign of hood for total enclosure; (2) the preventative maintenance schedule for ensuring the effectiveness of engineering control measures should be established; sensitive indicators for ultrafine particles need to be developed in occupational health examination; (3) the NIOSH-certified N95 or P100 filtering facepiece respirators should be used and regular inspection should be conducted to ensure workers are properly wearing the PPE.

\section{Conclusions}

In summary, the workers during cooking are at high risk due to exposure to high levels of ultrafine particles associated with working activity and with a bimodal size distribution. To reduce the risk, the existing control strategies, including engineering control, management control, and personal protection equipment need to be improved in this restaurant. The baseline data provided by this study can be used to develop standards for ultrafine particle exposure assessment and to design effective exposure controls in restaurants. More field investigations are needed to improve the exposure control strategies for the Chinese restaurant.

Received: 4 January 2021; Accepted: 13 July 2021

Published online: 02 August 2021

\section{References}

1. Gao, J., Cao, C., Zhang, X. \& Luo, Z. Volume-based size distribution of accumulation and coarse particles (PM0.1-10) from cooking fume during oil heating. Build. Environ. 59, 575-580 (2013).

2. Huang, Y. et al. Characteristics and health impacts of VOCs and carbonyls associated with residential cooking activities in Hong Kong. J. Hazard. Mater. 186(1), 344-351 (2011).

3. Chowdhury, Z. et al. Quantification of indoor air pollution from using cookstoves and estimation of its health effects on adult women in northwest Bangladesh. Aerosol Air Qual. Res. 12, 463-475 (2012).

4. See, S. W. \& Balasubramanian, R. Risk assessment of exposure to indoor aerosols associated with Chinese cooking. Environ. Res. 102(2), 197-204 (2006).

5. Buonanno, G., Morawska, L. \& Stabile, L. Particle emission factors during cooking activities. Atmos. Environ. 43(20), 3235-3242 (2009).

6. Torkmahalleh, M. A. et al. PM2.5 and ultrafine particles emitted during heating of commercial cooking oils. Indoor Air. 22(6), 483-491 (2012).

7. Wang, L. et al. Role of Chinese cooking emissions on ambient air quality and human health. Sci. Total Environ. 589, 173-181 (2017).

8. Liao, C. M., Chen, S. C., Chen, J. W. \& Liang, H. M. Contributions of Chinese-style cooking and incense burning to personal exposure and residential PM concentrations in Taiwan region. Sci. Total Environ. 358(1-3), 72-84 (2006).

9. Brown, J. S., Zeman, K. L. \& Bennett, W. D. Ultrafine particle deposition and clearance in the healthy and obstructed lung. Am. J. Res. Crit. Care 166(9), 1240-1247 (2002).

10. Gabdrashova, R., Nurzhan, S., Naseri, M., Bekezhankyzy, Z. \& Torkmahalleh, M. A. The impact on heart rate and blood pressure following exposure to ultrafine particles from cooking using an electric stove. Sci. Total Environ. 750, 141334 (2020).

11. Simkhovich, B. Z., Kleinman, M. T. \& Kloner, R. A. Air pollution and cardiovascular injury epidemiology, toxicology, and mechanisms. J. Am. Coll. Cardiol. 52(9), 719-726 (2008).

12. Juntarawijit, C. \& Juntarawijit, Y. Cooking smoke and respiratory symptoms of restaurant workers in Thailand. BMC Pulm. Med. 17(1), 41 (2017).

13. Chen, T. Y., Fang, Y. H., Chen, H. L., Chang, C. H. \& Hsiung, C. A. Impact of cooking oil fume exposure and fume extractor use on lung cancer risk in non-smoking Han Chinese women. Sci. Rep. 10(1), 6774 (2020).

14. Lu, F. et al. The emission of PM2.5 in respiratory zone from Chinese family cooking and its health effect. Sci. Total Environ. 654, 671-677 (2019).

15. Yu, K.-P., Yang, K. R., Chen, Y. C., Gong, J. Y. \& Lung, S. C. C. Indoor air pollution from gas cooking in five Taiwanese families. Build. Environ. 93, 258-266 (2015).

16. Benka-Coker, M. L. et al. Kitchen concentrations of fine particulate matter and particle number concentration in households using biomass cookstoves in rural Honduras. Environ. Pollut. 258, 113697 (2020).

17. Abdullahi, K. L., Delgado-Saborit, J. M. \& Harrison, R. M. Emissions and indoor concentrations of particulate matter and its specific chemical components from cooking: A review. Atmos. Environ. 71, 260-294 (2013).

18. Huang, X., Han, D., Cheng, J., Chen, X. \& Yuan, C. Characteristics and health risk assessment of volatile organic compounds (VOCs) in restaurants in Shanghai. Environ. Sci. Pollut. Res. Int. 27(1), 490-499 (2020).

19. Dai, W. et al. Characterization and health risk assessment of airborne pollutants in commercial restaurants in northwestern China: Under a low ventilation condition in wintertime. Sci. Total Environ. 633, 308-316 (2018).

20. Sanchez Jimenez, A. et al. A comparison of control banding tools for nanomaterials. J. Occup. Environ. Hyg. 13(12), 936-949 (2016).

21. Zalk, D. M., Paik, S. Y. \& Swuste, P. Evaluating the Control Banding Nanotool: A qualitative risk assessment method for controlling nanoparticle exposures. J. Nanoparticle Res. 11(7), 1685 (2009).

22. Eastlake, A., Zumwalde, R. \& Geraci, C. Can control banding be useful for the safe handling of nanomaterials? A systematic review. J. Nanoparticle Res. 18, 169 (2016).

23. Gao, X. et al. Qualitative and quantitative differences between common control banding tools for nanomaterials in workplaces. RSC Adv. 9(59), 34512-34528 (2019).

24. Brouwer, D. H. Control banding approaches for nanomaterials. Ann. Occup. Hyg. 56(5), 506-514 (2012).

25. Dunn, K. H., Eastlake, A. C., Story, M. \& Kuempel, E. D. Control banding tools for engineered nanoparticles: What the practitioner needs to know. Ann. Work Expo. Health. https://doi.org/10.1093/annweh/wxy002 (2018).

26. Lamon, L., Aschberger, K., Asturiol, D., Richarz, A. \& Worth, A. Grouping of nanomaterials to read-across hazard endpoints: A review. Nanotoxicology 13(1), 100-118 (2019). 
27. Van Duuren-Stuurman, B. et al. Stoffenmanager nano version 1.0: a web-based tool for risk prioritization of airborne manufactured nano objects. Ann. Occup. Hyg. 56(5), 525-41 (2012).

28. Zalk, D. M. et al. Risk level based management system: A control banding model for occupational health and safety risk management in a highly regulated environment. Ind. Health. 48(1), 18-28 (2010).

29. NIOSH. Current strategies for engineering controls in nanomaterial production and downstream handling processes. U.S. Department of Health and Human Services, Centers for Disease Control and Prevention, National Institute for Occupational Safety and Health, DHHS (NIOSH) Publication No. 2014-102 (2013).

30. Ministry of Emergency Management of the People's Republic of China. Technical specifications for test and evaluation of capture velocity for local exhaust ventilation facilities. Publication No. AQ/T4274 (2016).

31. Zhao, Y. \& Zhao, B. Emissions of air pollutants from Chinese cooking: A literature review. Build. Simul. 11, 977-995 (2018).

32. Huang, Y. et al. Household air pollution and personal inhalation exposure to particles (TSP/PM $(2.5) / \mathrm{PM}(1.0) / \mathrm{PM}(0.25))$ in rural Shanxi, North China. Environ. Pollut. 231(Pt 1), 635-643 (2017).

33. Wang, L. et al. Characterization particulate matter from several Chinese cooking dishes and implications in health effects. J. Environ. Sci. 72, 98-106 (2018).

34. Svendsen, K. et al. Exposure to cooking fumes in restaurant kitchens in Norway. Ann. Occup. Hyg. 46(4), 395-400 (2002).

35. Mitsakou, C. et al. Lung deposition of fine and ultrafine particles outdoors and indoors during a cooking event and a no activity period. Indoor Air 17(2), 143-152 (2007).

36. Xing, M. L. et al. Workplace exposure to airborne alumina nanoparticles associated with separation and packaging processes in a pilot factory. Environ. Sci. Process. Impacts 17, 656 (2015).

37. Zou, H. et al. Relationships between number, surface area, and mass concentrations of different nanoparticles in workplaces. Environ. Sci. Process. Impacts 17, 1470 (2015)

38. Morawska, L. et al. JEM spotlight: Environmental monitoring of airborne nanoparticles. J. Environ. Monit. 11, 1758-1773 (2009).

39. Chen, R. et al. Airborne nanoparticle pollution in a wire electrical discharge machining workshop and potential health risks. Aerosol Air Qual. Res. 15(1), 284-294 (2015).

40. Farmer, D. K. et al. Overview of HOMEChem: House observations of microbial and environmental chemistry. Environ. Sci. Proc. Impacts 21(8), 1280-1300 (2019).

41. Yao, Z. et al. Characteristics of PAHs from deep-frying and frying cooking fumes. Environ. Sci. Pollut. Res. Int. 22(20), 16110-16120 (2015).

42. Wang, X. Analysis on the influence of indoor air pollution on human health and prevention measures. In IOP Conference Series: Earth and Environment Science 300, 032059, (2019).

43. Xue, Y., Jiang, Y., Jin, S. \& Li, Y. Association between cooking oil fume exposure and lung cancer among Chinese nonsmoking women: a meta-analysis. OncoTargets Ther. 9, 2987-2992 (2016).

44. Zhang, J. et al. Distribution characteristics of and personal exposure with polycyclic aromatic hydrocarbons and particulate matter in indoor and outdoor air of rural households in Northern China. Environ. Pollut. 255(Pt 1), 113176 (2019).

\section{Acknowledgements}

The authors would like to acknowledge the Chinese restaurant.

\section{Author contributions}

X.G.: Investigation, funding acquisition, and writing original draft preparation. M.Z.: Review and editing. H.Z.: Investigation. Z.Z.: Supervision. W.Y.: Supervision. C.Q.: Supervision. Y.C.: Conceptualization, review, and editing. All authors read and approved the final manuscript.

\section{Funding}

This work was supported by the Medical Health Technology Project by the Health Commission of Zhejiang (No. 2020KY517 and 2021KY613), Open Fundation of Beijing Key Laboratory of Occupational Safety and Health (2021), Zhejiang Provincial Foundation Public Welfare Research Project (LGC21H260001), and Talent Incubation Project of the Center for Disease Control and Prevention of Zhejiang Province.

\section{Competing interests}

The authors declare no competing interests.

\section{Additional information}

Correspondence and requests for materials should be addressed to Y.C.

Reprints and permissions information is available at www.nature.com/reprints.

Publisher's note Springer Nature remains neutral with regard to jurisdictional claims in published maps and institutional affiliations.

(c) (i) Open Access This article is licensed under a Creative Commons Attribution 4.0 International cc) License, which permits use, sharing, adaptation, distribution and reproduction in any medium or format, as long as you give appropriate credit to the original author(s) and the source, provide a link to the Creative Commons licence, and indicate if changes were made. The images or other third party material in this article are included in the article's Creative Commons licence, unless indicated otherwise in a credit line to the material. If material is not included in the article's Creative Commons licence and your intended use is not permitted by statutory regulation or exceeds the permitted use, you will need to obtain permission directly from the copyright holder. To view a copy of this licence, visit http://creativecommons.org/licenses/by/4.0/.

(C) The Author(s) 2021 